\title{
Phenotypic variation of erythrocyte linker histone H1.c in a pheasant (Phasianus colchicus L.) population
}

\author{
Andrzej Kowalski ${ }^{1}$, Jan Pałyga ${ }^{1}$, Ewa Górnicka-Michalska ${ }^{1}$, Zenon Bernacki ${ }^{2}$ and Marek Adamski ${ }^{2}$ \\ ${ }^{1}$ Department of Biochemistry and Genetics, Jan Kochanowski University, Kielce, Poland. \\ ${ }^{2}$ Department of Poultry Breeding, University of Technology and Life Sciences, Bydgoszcz, Poland.
}

\begin{abstract}
Our goal was to characterize a phenotypic variation of the pheasant erythrocyte linker histone subtype H1.c. By using two-dimensional polyacrylamide gel electrophoresis three histone H1.c phenotypes were identified. The differently migrating allelic variants $\mathrm{H} 1 . \mathrm{c} 1$ and $\mathrm{H} 1$.c2 formed either two homozygous phenotypes, $\mathrm{c} 1$ and $\mathrm{c} 2$, or a single heterozygous phenotype, $\mathrm{c} 1 \mathrm{c} 2$. In the pheasant population screened, birds with phenotype $\mathrm{c} 2$ were the most common (frequency 0.761 ) while individuals with phenotype $c 1$ were rare (frequency 0.043 ).
\end{abstract}

Key words: linker histones, H1.c subtype, allelic variants, electrophoresis.

Received: November 5, 2009; Accepted: March 17, 2010.

Linker histones, also known as $\mathrm{H} 1$ histones, are members of a protein family composed of small $(\sim 21.5 \mathrm{kDa})$ and abundant ( $\sim .8 \mathrm{H} 1 /$ nucleosome) basic proteins, located in the eukaryotic chromatin (Woodcock et al., 2006). In the past, they were mainly recognized as structural components involved in stabilizing nucleosomal arrays and folding chromatin fiber into more compacted states (Widom, 1998; Hansen, 2002;). However, a contribution of histone H1 to other nuclear events, such as specific gene regulation (Lee et al., 2004), DNA methylation (Fan et al., 2005) or cell cycle disruption (Sancho et al., 2008), was also demonstrated. As highly mobile proteins, the members of the histone H1 family can compete with other structural (Catez et al., 2004) and regulatory proteins (Kim et al., 2008) to change their activity in a dynamic network of chromatin interactions (Bustin et al., 2005).

Higher eukaryotes have at least six somatic histone H1 subtypes (van Holde, 1989), encoded by separate genes intermingled with core histone genes (Nakayama et al., 1993). H1 histone variants usually differ in amino acid sequence in less structured $\mathrm{N}$-terminal and C-terminal domains and occasionally in highly conservative and structured central globular domain (Ponte et al., 1998). The avian family of somatic linker histones, composed of at least six to seven non-allelic subtypes that can be identified according to the rate of their electrophoretic migration in polyacrylamide gels (Palyga, 1991a), may differ in the number of components in different species. While faster moving histone H1 subtypes H1.c, H1.c' and H1.d

Send correspondence to Andrzej Kowalski. Department of Biochemistry and Genetics, Jan Kochanowski University, Swietokrzyska 15, 25-406 Kielce, Poland. E-mail: a.kowalski@ ujk.kielce.pl. were found to be present in every species tested, the slower migrating subtypes H1.a', H1.b' and H1.z were occasionally missing. For example, histone H1 subtype H1.z that is present in ducks (Palyga et al., 1993), quails (Palyga, 1998a) and many other species (Palyga, 1991a) has not been observed in chickens (Górnicka-Michalska et al., 2006) and partridges (Kowalski et al., 2008). A comparison of the gel patterns of avian $\mathrm{H} 1$ histones demonstrated that species-specific components possessed slightly higher molecular weights, and hence migrated slower, than faster moving subtypes that tended to arrange in a triangle-shaped pattern (Palyga, 1991a). In addition, a polymorphic variation was found to be typical for histone subtypes H1.a (Kowalski et al., 1998; Palyga, 1998a; Górnicka-Michalska et al., 2006), H1.a' (Kowalski et al., 2008), H1.b (Palyga, 1998a; Palyga et al., 2000; ) and H1.z (Palyga et al., 1993; Palyga, 1998a; Kowalski et al., 2004) in several avian species, whereas the histone subtypes H1.c, H1.c' and H1.d were relatively invariant in all species tested so far.

In this study, we show that pheasant erythrocyte histone H1.c is a heterogeneous protein with two allelic variants, H1.c1 and H1.c2, which occur as homozygous, c1 and $\mathrm{c} 2$, and heterozygous, $\mathrm{c} 1 \mathrm{c} 2$, phenotypic combinations.

The study was carried out using a group of 46 pheasants (Phasianus colchicus L.) bred at the Department of Poultry Breeding of the University of Technology and Life Sciences at Bydgoszcz, Poland. Erythrocytes were isolated from a cell suspension consisting of $1 / 3$ of whole blood and $2 / 3$ of SSC solution $(0.15 \mathrm{M} \mathrm{NaCl}, 0.015 \mathrm{M}$ sodium citrate) by triple washing with SSC. Erythrocyte nuclei were pre- 
pared by lysis with a $3 \%$ saponin solution buffered with 0.1 $\mathrm{M}$ sodium phosphate, $\mathrm{pH}$ 7.0. After washing the nuclear pellet several times with $0.9 \% \mathrm{NaCl}$, the total acid-soluble fraction containing mainly histone $\mathrm{H} 1$ proteins was isolated by double extraction of the crude nuclear pellet with perchloric acid, first with a $1 \mathrm{M}$ and then with a $0.5 \mathrm{M}$ solution. The protein was precipitated with trichloroacetic acid, then the pellet was washed, first with acetone acidified with $\mathrm{HCl}$ and finally with pure acetone, and air-dried.

Electrophoresis samples, prepared by dissolving 1-mg aliquots of a total histone $\mathrm{H} 1$ protein preparation in $200 \mu \mathrm{L}$ of a solution containing $8 \mathrm{M}$ urea, $0.9 \mathrm{M}$ acetic acid and $10 \% 2$-mercaptoethanol, were submitted to two-dimensional polyacrylamide gel electrophoresis. First, the total protein was resolved in a $15 \%$ acrylamide gel containing $8 \mathrm{M}$ urea and $0.9 \mathrm{M}$ acetic acid in the first dimension, and then in a $13.5 \%$ acrylamide gel prepared with $0.1 \%$ sodium dodecylsufate (SDS) in the second dimension, according to the detailed description of Palyga (1991b). The gels were stained with Coomassie Blue R-250 and images taken by means of a Doc-Print II gel documentation system (Vilber Lourmat).

Total preparations of pheasant histone $\mathrm{H} 1$, containing H1.c and other H1 subtypes, obtained from saponin-lysed erythrocyte nuclei by perchloric acid extraction, were separated both by one-dimensional and two-dimensional polyacrylamide gel electrophoresis (Figure 1A). A comparison of the electrophoretic mobility of a faintly stained band of histone H1.c (band c2) of the pheasant population in the acetic acid-urea polyacrylamide gel (Figure 1A) revealed that it was missing in some individuals, while the histone H1.c spots in the two-dimensional gel were clearly present in all individuals (Figure 1B). Therefore, it appears that pheasant erythrocyte histone H1.c is a heterogeneous protein with a presumed polymorphic variation, while the other histone H1 non-allelic subtypes, H1.a, H1.b, H1.b', H1.c' and H1.d, are monomorphic proteins (Figure 1). The electrophoretic migration of H1.c is determined by the mobility of its allelic complements, H1.c1 and H1.c2, in a particular type of gel. A slow isoform, H1.c1, migrated along with the subtype H1.b in the first dimension and was positioned further away from the nearest moving subtype H1.d in the second dimension, whereas the fast isoform, H1.c2, migrated slightly below the subtype H1.b' in the first dimension and in a direct vicinity of subtype H1.d in the second dimension (Figure 1C). The histone H1.c heterogeneity detected in the acetic acid-urea gel may result from differences in a net charge between the allelic isoforms H1.c1 and H1.c2. Previously, by using acid-urea polyacrylamide gel, we disclosed the polymorphisms of histone H1.a in ducks (Kowalski et al., 1998) and chickens (GórnickaMichalska et al., 2006). In both cases, two allelic variants, H1.a1 and H1.a2, formed three phenotypes, a1, a2 and a1a2, which appeared to be differently distributed in the avian breeds and/or genetic groups tested. Most of the duck

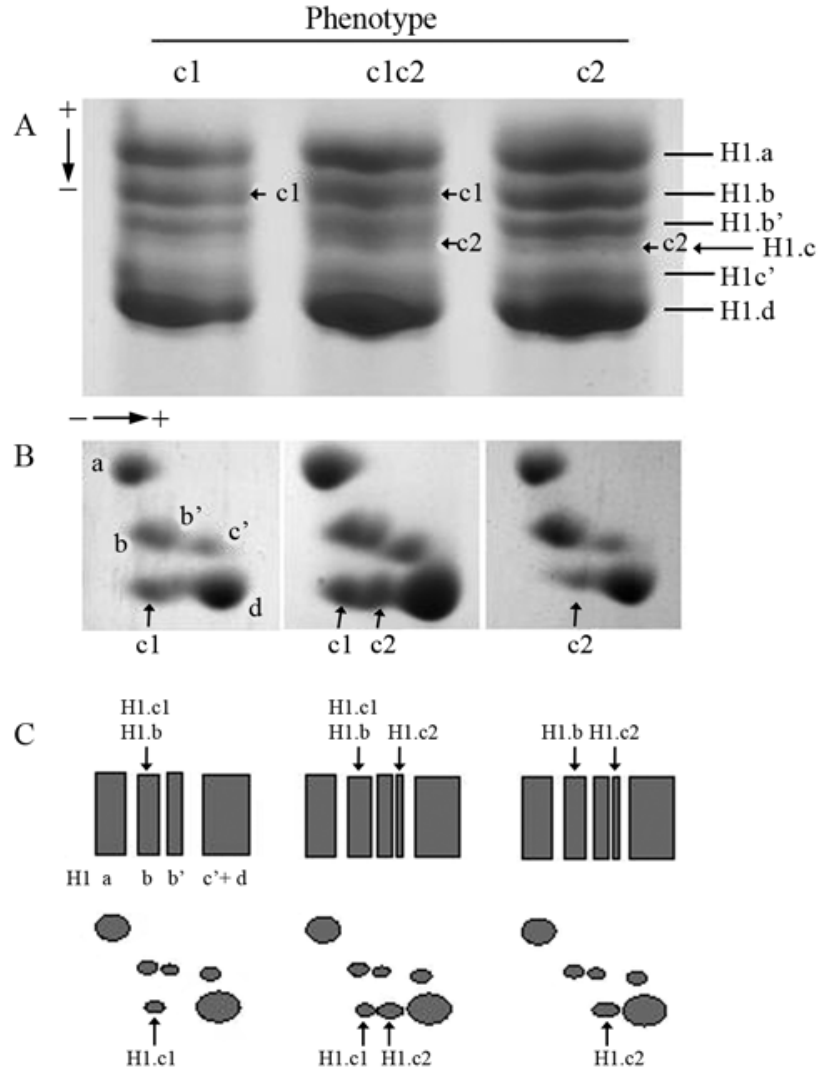

Figure 1 - Phenotypic variation of pheasant histone H1.c in one-dimensional (A) and two-dimensional (B) gels. Identified phenotypes of histone H1.c (c1, c2 and $\mathrm{c} 1 \mathrm{c} 2)$ are composed of a single band (A) or spot (B) of allelic isoform H1.c1 (homozygous phenotype c1) or allelic isoform H1.c2 (homozygous phenotype c2), or a double band (A) or spot (B) containing both isoforms H1.c1 and H1.c2 (heterozygous phenotype c1 c2). In the acetic acid-urea gel, the isoform H1.c1, comigrating with subtype H1.b, moved slower than the fast isoform H1.c2, migrating slightly below subtype H1.b', while both variants exhibited the same rate of electrophoretic migration (and presumably similar molecular weights) in the SDS gel, but were differently located in relation to the H1.d spot (C).

and chicken specimens were found to possess an abundant phenotype a1, which was the only form of histone H1.a in some avian flocks. A rare phenotype, a2, was present at a frequency below $10 \%$ in several duck groups (Kowalski et $a l ., 1998)$ and has not been detected in any chicken population (Górnicka-Michalska et al., 2006). In the latter, the structural properties of the allelic isoform H1.a2 were analyzed using preparations obtained from homozygous a 2 individuals using progeny of purpose-mated heterozygous parents (unpublished). In the pheasant population tested, the allelic isoforms of histone H1.c were found to be arranged into three phenotypes. In particular, the isoforms $\mathrm{H} 1 . \mathrm{c} 1$ and H1.c2 were constituents of homozygous phenotypes $\mathrm{c} 1$ and $\mathrm{c} 2$, respectively, or combined together to constitute the heterozygous phenotype c1c2 (Figure 1). Among the 46 pheasants tested, the majority (35 individuals) was represented by homozygotes for isoform H1.c2 (frequency $=0.761$ ), while the heterozygotes ( 9 individuals) with both isoforms H1.c1 and H1.c2 (frequency $=0.195$ ) and homo- 
Table 1 - Phenotype and allele frequencies of pheasant erythrocyte histone H1.c.

\begin{tabular}{lcccc}
\hline Histone H1.c phenotype & \multicolumn{2}{c}{$\mathrm{N}^{\mathrm{o}}$ of individuals } & Phenotype frequency & \multicolumn{2}{c}{ Allele frequency } \\
\cline { 3 - 5 } & & & $c^{1}$ & $c^{2}$ \\
\hline $\mathrm{c} 1$ & 2 & 0.043 & \\
$\mathrm{c} 2$ & 35 & 0.761 & 0.141 & 0.858 \\
$\mathrm{c} 1 \mathrm{c} 2$ & 9 & 0.195 & & \\
\hline
\end{tabular}

zygotes for isoform H1.c1 (frequency $=0.043$ ) were minority. Thus, in the pheasant population tested, the prevailing allele $c^{2}$ (frequency $=0.858$ ) was found to occur at a frequency more than six times higher than that of the rare allele $c^{1}$ (frequency $\left.=0.141\right)($ Table 1$)$.

Various combinations of allelic components of the polymorphic histone $\mathrm{H} 1$ subtypes have been identified in several avian species, including ducks (Palyga et al., 1993; Kowalski et al., 1998), quails (Palyga, 1998a), chickens (Górnicka-Michalska et al., 2006), and partridges (Kowalski et al., 2008). Due to differences, either in net charge and/or in molecular weight, the allelic isoforms could be distinguished based on their electrophoretic migration in polyacrylamide gels. Usually, two or three allelic variants which might form three or six phenotypes, respectively, were detected in the populations tested. For example, polymorphic duck subtypes H1.a (Kowalski et al., 1998) and H1.z (Palyga et al., 1993), each composed of two allelic isoforms, formed three phenotypes, while Peking duck histone H1.b (Palyga et al., 2000) and Muscovy duck histone H1.z (Kowalski et al., 2004), with three allelic isoforms each, were combined to form six phenotypes.

A variation in the frequency of phenotypes and alleles among polymorphic histone H1 subtypes was observed in several avian populations (Palyga et al., 1993; Kowalski et al., 2004; Górnicka-Michalska et al., 2006; Kowalski et al., 2008). The allele frequency was also found to correlate with a selection aimed at improving some usable traits in poultry breeding (Palyga, 1998b; Palyga et al., 2000). Moreover, we observed (unpublished data) a tendency to decrease heterozygosity, almost by half for subtype H1.b, and more than five times for subtype H1.z, between quails selected for a high cholesterol content in the eggs (Baumgartner et al., 2007) and an unselected quail population. These and other selection results (Palyga, 1998b) seem to suggest that some histone $\mathrm{H} 1$ polymorphic subtypes may affect the mechanisms and/or processes underlying the breeding traits and the quality of animal products. As even slight changes in the histone $\mathrm{H} 1$ primary structure can influence chromatin properties (Bharath et al., 2003; Hendzel et al., 2004), it seems that a small structural difference between histone $\mathrm{H} 1$ allelic variants may modify their binding to chromatin, possibly modulating chromatin remodeling and regional gene regulation.

\section{References}

Allan J, Hartman PG, Crane-Robinson C and Aviles FX (1980) The structure of histone $\mathrm{H} 1$ and its location in chromatin. Nature 288:675-679.

Bharath MM, Chandra NR and Rao MR (2003) Molecular modeling of the chromatosome particle. Nucleic Acids Res 31:4264-4274.

Baumgartner J, Koncekova Z and Benkova J (2007) Line effect and phenotypic correlations among egg qualitative traits in Japanese quail eggs selected on yolk cholesterol content. Slovak J Anim Sci 40:13-18.

Bustin M, Catez F and Lim JH (2005) The dynamics of histone H1 function in chromatin. Mol Cell 17:617-620.

Catez F, Yang H, Tracey KJ, Misteli T and Bustin M (2004) Network of dynamic interactions between histone $\mathrm{H} 1$ and highmobility-group proteins in chromatin. Mol Cell Biol 24:4321-4328.

Fan Y, Nikitina T, Zhao J, Fleury TJ, Bhattacharyya R, Bouhaasira EE, Stein A, Woodcock CI and Skoultchi AI (2005) Histone $\mathrm{H} 1$ depletion in mammals alter global chromatin structure but causes specific changes in gene regulation. Cell 123:1199-1212.

Górnicka-Michalska E, Palyga J, Kowalski A and Cywa-Benko K (2006) Sequence variants of chicken linker histone H1.a. FEBS J 273:1240-1250.

Hansen JC (2002) Conformational dynamics of the chromatin fiber in solution: Determinants, mechanisms and functions. Annu Rev Biophys Biomol Struct 31:361-392.

Hendzel MJ, Lever MA, Crawford E and Th'ng JP (2004) The $\mathrm{C}$-terminal domain is the primary determinant of histone $\mathrm{H} 1$ binding to chromatin in vivo. J Biol Chem 279:2002820034.

Kim K, Choi J, Heo K, Kim H, Levens D, Kohno K, Johnson EM, Brock HW and An W (2008) Isolation and characterization of a novel H1.2 complex that acts as a repressor of p53mediated transcription. J Biol Chem 283:9113-9126.

Kowalski A, Palyga J, Górnicka-Michalska E and Krajewska WM (1998) Allelic polymorphism of histone H1.a in duck erythrocytes. Biochem Genet 36:163-191.

Kowalski A, Palyga J and Górnicka-Michalska E (2004) Identification of histone H1.z components in a Muscovy duck (Cairina moschata L.) population. Comp Biochem Physiol B 137:151-157.

Kowalski A, Palyga J and Górnicka-Michalska E (2008) Polymorphic isoforms of erythrocyte histone H1.a' in a Grey partrigde population. J Agrobiol 25:125-128.

Lee H, Habas R and Abate-Shen C (2004) MSX1 cooperates with histone $\mathrm{H} 1 \mathrm{~b}$ for inhibition of transcription and myogenesis. Science 304:1675-1678. 
Nakayama T, Takechi S and Takami Y (1993) The chicken histone gene family. Comp Biochem Physiol B 104:635-639.

Palyga J (1991a) A comparison of the histone H1 complements of avian erythrocytes. Int J Biochem 23:845-849.

Palyga J (1991b) Genetic polymorphism of histone H1b in duck erythrocytes. Hereditas 114:85-89.

Palyga J (1998a) Genes for polymorphic H1 histones are linked in the Japanese quail genome. Biochem Genet 36:93-103.

Palyga J (1998b) Distribution of allelic forms of erythrocyte H1 histones in Japanase quail populations divergently selected for amount of weight loss after transient starvation. Biochem Genet 36:79-92.

Palyga J, Górnicka-Michalska E and Kowalski A (1993) Genetic polymorphism of histone H1.z in duck erythrocytes. Biochem J 294:859-863.

Palyga J, Górnicka-Michalska E, Kowalski A and Ksikiewicz J (2000) Natural allelic variation of duck erythrocyte histone H1.b. Int J Biochem Cell Biol 32:665-675.
Ponte I, Vidal-Taboada JM and Suau P (1998) Evolution of the vertebrate $\mathrm{H} 1$ histone class: Evidence for the functional differentiation of the subtypes. Mol Biol Evol 15:702708.

Sancho M, Diani E, Beato M and Jordan A (2008) Depletion of human histone $\mathrm{H} 1$ variants uncovers specific roles in gene expression and cell growth. PloS Genetics 4:1-17

van Holde K (1989) Chromatin. Springer Verlag, New York, $497 \mathrm{pp}$.

Widom J (1998) Chromatin structure: Linking structure to function with histone H1. Curr Biol 8:R788-R791.

Woodcock CL, Skoultchi AI and Fan Y (2006) Role of linker histone in chromatin structure and function: H1 stoichiometry and nucleosome repeat length. Chromosome Res $14: 17-25$.

Editor: Angela M. Vianna Morgante

License information: This is an open-access article distributed under the terms of the Creative Commons Attribution License, which permits unrestricted use, distribution, and reproduction in any medium, provided the original work is properly cited. 